\title{
Missed opportunity for standardized diagnosis and treatment among adult Tuberculosis patients in hospitals involved in Public-Private Mix for Directly Observed Treatment Short-Course strategy in Indonesia: a cross-sectional study
}

\author{
Ari Probandari*1,2,4, Lars Lindholm²,4, Hans Stenlund², Adi Utarini ${ }^{\dagger 3}$ and Anna-Karin Hurtig ${ }^{\dagger 2,4}$
}

\begin{abstract}
Background: The engagement of hospitals in Public-Private Mix (PPM) for Directly Observed Treatment Short-Course (DOTS) strategy has increased rapidly internationally - including in Indonesia. In view of the rapid global scaling-up of hospital engagement, we aimed to estimate the proportion of outpatient adult Tuberculosis patients who received standardized diagnosis and treatment at outpatients units of hospitals involved in the PPM-DOTS strategy.

Methods: A cross-sectional study using morbidity reports for outpatients, laboratory registers and Tuberculosis patient registers from 1 January 2005 to 31 December 2005. By quota sampling, 62 hospitals were selected. Post-stratification analysis was conducted to estimate the proportion of Tuberculosis cases receiving standardized management according to the DOTS strategy.

Result: Nineteen to $53 \%$ of Tuberculosis cases and $4-18 \%$ of sputum smear positive Tuberculosis cases in hospitals that participated in the PPM-DOTS strategy were not treated with standardized diagnosis and treatment as in DOTS.

Conclusion: This study found that a substantial proportion of TB patients cared for at PPM-DOTS hospitals are not managed under the DOTS strategy. This represents a missed opportunity for standardized diagnoses and treatment. A combination of strong individual commitment of health professionals, organizational supports, leadership, and relevant policy in hospital and National Tuberculosis Programme may be required to strengthen DOTS implementation in hospitals.
\end{abstract}

\section{Background}

The World Health Organization (WHO) has promoted the Directly Observed Treatment Short-Course (DOTS) strategy at the international level since the mid-1990s, and it has proved a cost-effective strategy to combat Tuberculosis (TB) [1-3]. DOTS strategy consists of five strategic pillars:

- Political commitment,

- Case detection by quality-assured sputum microscopy,

\footnotetext{
*Correspondence: ariprobandari@yahoo.com

1 Department of Public Health, Faculty of Medicine, Universitas Sebelas Maret,

JI. Ir. Sutami 36A, Surakarta 57126 Indonesia

+ Contributed equally

Full list of author information is available at the end of the article
}

- Standardized short-course chemotherapy under direct observation of treatment,

- Quality-assured drugs,

- Recording and reporting system [4].

However, the implementation of DOTS strategy by public health facilities is insufficient to ensure the notification of all TB cases in the community as well as to provide adequate treatment and prevent further transmission $[5,6]$.

Tuberculosis (TB) patients can receive care from a wide array of services, such as community health centres, general practitioners, traditional healers, chest clinics, and hospitals [7-11]. These facilities, however, do not necessarily implement the internationally-recommended 
DOTS strategy nor link to the National TB Programme. Evidence shows that without proper linkage to National TB Programme, these facilities are in fact providing poor quality diagnoses and treatment [12-15]. The need to engage different care providers in providing $\mathrm{TB}$ services is therefore urgent and the Public-Private Mix (PPM) for the DOTS initiative by $\mathrm{WHO}$ has been launched in response to this challenge $[10,16]$.

Hospitals in particular play a major role as a source of TB treatment in many high-burden countries $[11,17,18]$; thus hospitals have been identified as priority targets for PPM-DOTS initiatives. Public-general and medical-college hospitals are the two types of health care providers most engaged in PPM-DOTS schemes [19]. Improved case detection and treatment outcome has been noted in several countries as the result of involving hospitals in PPM-DOTS strategy [19-22]. This favourable outcome has led to rapid scaling-up of hospital involvement. The number of high-burden countries adopting the hospital PPM-DOTS approach at the national level increased rapidly from 4 to 14 countries during 2005-2007 [19]; Indonesia is no exception, with an increase from $31 \%$ in 2005 (two years after the scaling up) to $37 \%$ of hospitals involved in PPM-DOTS by early 2007 (Unpublished data from Ministry of Health Republic of Indonesia).

Several publications have raised concerns regarding the quality of DOTS strategy implementation in hospitals $[17,18,23-25]$. Poor compliance with diagnostic and treatment guidelines, and the increase of Multi-Drug-Resistant-TB, further raises concerns about quality $[18,24]$. In view of the rapid global scaling-up of hospital engagement, we aimed to analyse the access to DOTS based services in hospitals already involved in PPM-DOTS strategy in Indonesia by determining the proportion of outpatient adult TB patients who actually received standardized diagnosis and treatment.

\section{Methods \\ Study design}

This was a cross-sectional study that was part of a larger research entitled: Assessment of the implementation of DOTS strategy in hospitals in six provinces on Java Island, Indonesia. The study was conducted from August 2006 to July 2007, with a pilot-study organized in three hospitals located in two provinces (Central Java and Yogyakarta).

Figure 1 describes the flow of patients and information about TB patients in hospitals. Depending on the main symptoms, TB suspects may have different entrances when using the outpatient service. They may visit general outpatient service or more specialized outpatient units (such as pulmonary, internal medicine, neurology, and surgery) prior to visiting a specially designated DOTS unit. To confirm the diagnosis, ideally a sputum smear

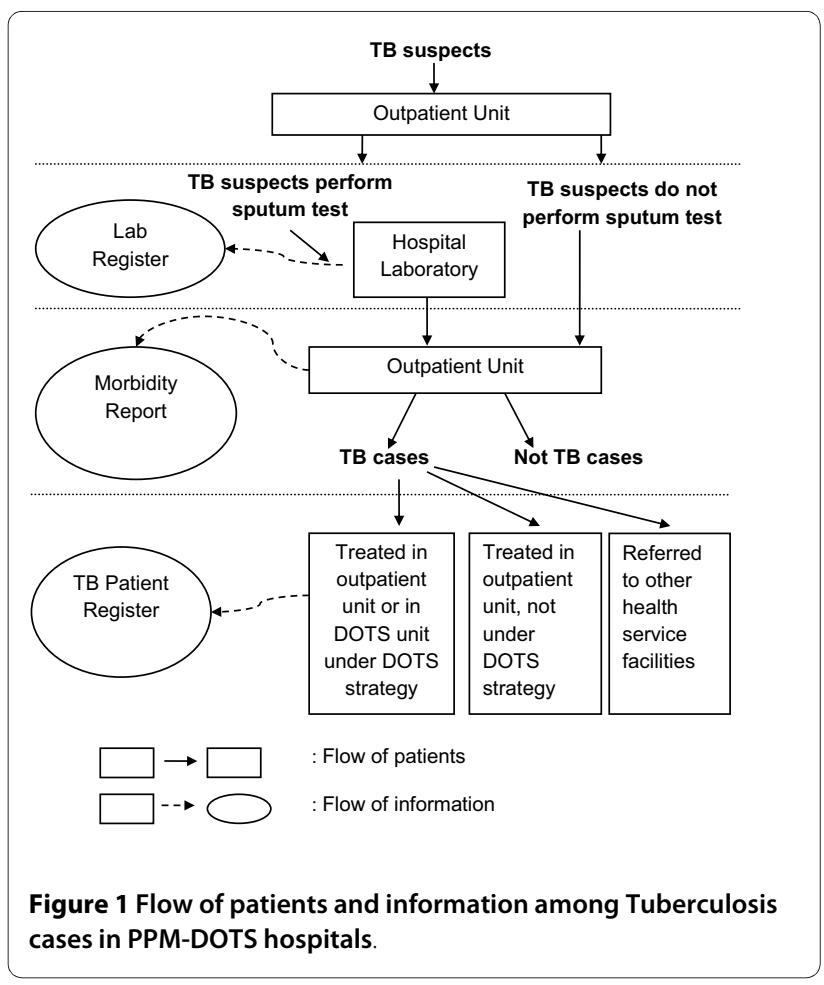

examination should first be carried out and the results recorded in the laboratory register [26]. A certain proportion of TB suspects may also have to undertake other diagnostic tests simultaneously, most commonly a chest $\mathrm{X}$-ray $[17,18,27]$. After completing the diagnostic tests, TB suspects return to the outpatient unit they initially visited. The diagnosis is recorded in the medical record, and later sent to the medical record department for the purpose of coding using the International Classification of Diseases (ICD) system. TB diagnoses are coded as ICD X A.15-A.19. However, it has been observed that the majority of hospitals do not record the specific ICD code but merge into a group of ICD codes for Tuberculosis. Based on the medical records, the hospital produces quarterly morbidity reports, including TB.

For treatment of TB patients, there are three possible scenarios. First, not all TB patients are managed in an outpatient unit with proper diagnosis and close monitoring of treatment using standardized TB patient register as in the DOTS strategy. Secondly, TB patients are treated with DOTS strategy in the unit where the patients were originally diagnosed or in the hospital DOTS unit (if available). Finally, confirmed TB patients are referred to other DOTS facilities closer to the patients' homes (such as to a community health centre). Due to incomplete recording of TB referrals from hospitals to other DOTS facilities, this study used the assumption of the referral rate from a study in Yogyakarta [22]. The median referral rate among hospitals during 2003-2005 was 31.5\% for all 
TB cases and $32.6 \%$ for sputum smear positive TB cases [22].

For those treated with DOTS strategy, the TB patient registers are then sent to the TB supervisor at the District Health Office and the information is further aggregated at the province and national levels.

\section{Data collection}

Trained surveyors collected the morbidity reports, laboratory registers and TB patient registers from the hospitals. Data from registers were double-entered. In order to improve the validity of data, the trained surveyors contacted the medical record staff to guarantee the completeness of the data and to clarify any issues arising.

\section{Study population, sampling strategy and sample}

The study population included hospitals participating in PPM-DOTS strategy based on 2006 data from the National TB Programme in Indonesia. It consisted of 72 public general hospitals, 70 private general hospitals, and 8 pulmonary hospitals in Java Island, Indonesia. Providers from all these hospitals had taken part in standardized DOTS training activities conducted by the National TB Programme.

The sampling for the larger study was carried out using quota sampling. The quota was determined by consideration of the proportion, type, and ownership of PPMDOTS hospitals among Java Island provinces. Based on type and ownership, the hospitals were differentiated into public general hospitals, private general hospitals, and public pulmonary hospitals. For this paper, we included hospitals in the study population which had been involved in PPM-DOTS for at least two years prior to 2006 , and which had both a TB recording and reporting system and an outpatient-morbidity report system in place. Sixty-two hospitals met the inclusion criteria.

\section{Analyses}

The analyses included, firstly, demographic characteristics of TB cases for each hospital group and evaluation of the differences by Kruskall Wallis tests and, secondly, post-stratification analysis to estimate the proportion of TB cases not treated under a DOTS unit. Post-stratification analysis estimated the weighted cumulative number of TB cases in the morbidity report and patient register as well as cases who were sputum smear-positive in the laboratory and TB registers. To calculate the post-stratification weight, the number of hospitals in the study population was divided by the number of sampled hospitals. The weighted cumulative number of TB cases was then estimated by multiplying the post-stratification weight by the cumulative number of estimated TB cases in the sample.

\section{Ethics}

Approval for the study's ethics was received from Universitas Gadjah Mada, Indonesia. Permission for accessing the hospital registers was obtained from the local governments and hospitals. Patient confidentiality was assured during data analyses and presentation of study findings. The findings were shared with the hospitals, District-Provincial Health Offices and the National TB Programme.

\section{Results}

The numbers of hospitals sampled were: 31 public general hospitals, 29 private general hospitals, and 2 pulmonary hospitals. All included hospitals have access to the National TB Programme guidelines and manual. Nevertheless, this does not mean that the hospitals have already integrated the National TB Programme guidelines into their standard operating procedure for TB patients seeking care at the hospital (Table 1). Not all hospitals have a formal Memorandum of Understanding for the implementation of the DOTS strategy.

The number of TB cases from the morbidity reports, laboratory registers and TB patient registers had a skewed distribution. In general, public pulmonary hospitals registered a higher number of TB cases per hospital compared to general hospitals. The medians were 712 in pulmonary hospitals, 247 in public general hospitals and 102 in private general hospitals $(\mathrm{p}=0.03)$ (Table 2$)$. Furthermore, the total number of TB cases $(n=349)$ registered in pulmonary hospital DOTS units was higher than in public $(n=52)$ or private $(n=19)$ general hospitals $(p=$ 0.01 ). Similarly, the number of sputum smear positive TB cases identified by the pulmonary hospital laboratories ( $\mathrm{n}$ $=198)$ was greater than in public $(n=43)$ or private $(n=$ 17) general hospitals $(\mathrm{p}=0.001)$. A similar pattern was found for the number of sputum smear positive TB cases undergoing treatment at DOTS units $(\mathrm{p}=0.004)$.

Results of the post-stratification analysis showed the discrepancy between the number of TB cases recorded in the TB patient register and those in the hospital morbidity report. After adjusting for the referral rate, the proportion of TB cases not recorded in TB patient register was 53\% (in public general hospitals) and 52\% (in private general hospitals). This proportion was larger in general hospitals than that in public pulmonary hospitals (i.e. 19.5\%) (Table 3).

After considering the referral rate, the gap between the number of sputum smear positive TB cases recorded in the laboratory register and those recorded in the $\mathrm{TB}$ patient register ranged from $4 \%$ to $18 \%$. The highest proportion was in public general hospitals, followed by public pulmonary hospital and private general hospitals (18.2\%, $8.1 \%$, and $4.2 \%$ respectively) (Table 3 ). 
Table 1: Characteristics of hospitals in the sample.

\begin{tabular}{|c|c|c|c|c|c|c|}
\hline \multirow[t]{2}{*}{ Characteristic } & \multicolumn{2}{|c|}{$\begin{array}{l}\text { Public general hospitals } \\
\qquad(\mathrm{n}=\mathbf{3 1})\end{array}$} & \multicolumn{2}{|c|}{$\begin{array}{l}\text { Private general hospitals } \\
\qquad(\mathrm{n}=29)\end{array}$} & \multicolumn{2}{|c|}{$\begin{array}{l}\text { Public pulmonary hospitals } \\
\qquad(\mathrm{n}=2)\end{array}$} \\
\hline & $\mathbf{n}$ & $\%$ & $\mathbf{n}$ & $\%$ & $\mathbf{n}$ & $\%$ \\
\hline \multicolumn{7}{|l|}{$\begin{array}{l}\text { Outpatient visits } \\
\text { per year }\end{array}$} \\
\hline$<12,000$ & 5 & 16.2 & 12 & 41.4 & 0 & 0 \\
\hline $12,000-120,000$ & 22 & 71.0 & 15 & 51.7 & 2 & 100 \\
\hline$>120,000$ & 4 & 12.9 & 2 & 6.9 & 0 & 0 \\
\hline $\begin{array}{l}\text { Had NTP* guidelines } \\
\text { and manual }\end{array}$ & 31 & 100 & 29 & 100 & 2 & 100 \\
\hline $\begin{array}{l}\text { Had Standard of } \\
\text { Operating Procedure for } \\
\text { adult TB patients }\end{array}$ & 23 & 74.2 & 16 & 55.2 & 1 & 50 \\
\hline Had MoU** & 12 & 38.7 & 13 & 44.8 & 0 & 0 \\
\hline
\end{tabular}

${ }^{*} \mathrm{NTP}=$ the National Tuberculosis Program; ${ }^{*} \mathrm{MoU}=$ document of Memorandum of Understanding with the National Tuberculosis Programme.

\section{Discussion}

The findings show sub-optimal access to the DOTS strategy among TB patients in hospitals involved in the PPMDOTS initiative. This inconsistent access to DOTS strategy is more prominent in public general hospital whereas the general and medical college hospitals are the most common type of hospitals involved in PPM-DOTS [19]. A similar phenomenon was also reported in a study by Loveday et al. (2008), which found that $58 \%$ of smear positive TB cases did not access standardized National TB Programme treatment in the hospitals [18]; this could be due to a lack of cooperation in the application of diagnosis and treatment based on DOTS strategy for all TB patients [15,28], perceived complexity of DOTS based diagnosis and treatment [29], and perceived low quality of services due to provision of free TB drugs [29].

Taking into account the reliance on secondary data in this study, the findings still raise the issue of missed opportunity for PPM-DOTS hospitals to deliver quality diagnosis and treatment for all TB suspects. This could lead to misdiagnosis of TB patients and, consequently, improper treatment of TB patients. With the present, and alarming, problem of multiple-drug-resistant TB $[18,24]$, low quality of TB case management in hospitals implementing PPM-DOTS strategy certainly requires urgent attention. Therefore, we argue that a better balance is required between the expansion of PPM-DOTS strategy to new hospitals, and improvement of quality DOTS strategy implementation in existing hospitals.

Since services for TB patients can be delivered at several outpatient units in collaboration with other units (DOTS units, laboratories, medical records units, etc), the findings also reflected the complexity of internal linkages between those different micro systems involved in delivering TB care in hospitals. Several factors may contribute to the weakening of internal linkages, i.e. from micro system to organization level, up to the policy at the national level. At the micro system level, individual commitment of health professionals [25], as well as teamwork, information, performance and improvement, and clinical leadership [30] are key factors. Subsequently, hospital and National Tuberculosis Programme policies that help to support and strengthen those factors (in order to improve quality) are critical.

Different mechanisms exist to enhance the quality of DOTS strategy implementation in hospitals. At the micro system level, launching of the International Standard for TB Care can be an initial bridge for improving the commitment of health professionals involved in delivering TB care [31,32]. Endorsement from professional organizations and operational support to ensure implementation of the International Standard for TB Care among specialists are required [33]. Staff incentives are important to focus the staff on providing high quality services to patients [30]. However, there is limited evidence of the types of incentives that are effective in the context of PPM-TB control [34,35]. At the hospital level, Siddiqi et al. (2008) implemented TB clinical audit as a process measurement for improving clinical TB care [36]. Experience in the Philippines suggests that national level regulations such as accreditation and certification of PPMDOTS hospitals can also be effective in improving the quality of TB services [34]. Finally, existing mechanisms in TB control management, i.e. internal and external 
Table 2: Number of Tuberculosis cases: comparison of morbidity reports, laboratory registers and TB patient registers at general hospitals and pulmonary hospitals, 2005.

\begin{tabular}{|c|c|c|c|c|}
\hline & $\begin{array}{l}\text { Public general } \\
\text { hospital }\end{array}$ & $\begin{array}{l}\text { Private general } \\
\text { hospital }\end{array}$ & $\begin{array}{l}\text { Public } \\
\text { pulmonary } \\
\text { hospital }\end{array}$ & All hospitals \\
\hline Number of hospitals & 31 & 29 & 2 & 62 \\
\hline \multicolumn{5}{|c|}{ TB* cases in morbidity report $(n)^{* *}$} \\
\hline Median (min-max) & $247(5-1,601)$ & $102(5-1,584)$ & $712(631-793)$ & $211(5-1,601)$ \\
\hline Cumulative & 11,223 & 6,843 & 1,424 & 19,490 \\
\hline \multicolumn{5}{|c|}{ TB cases in TB patient register ( $\mathrm{n}$ ) } \\
\hline Median (min-max) & $52(1-169)$ & $19(2-170)$ & $349(264-434)$ & $37.5(1-434)$ \\
\hline Cumulative & 1,710 & 1,140 & 698 & 3,522 \\
\hline \multicolumn{5}{|c|}{$\begin{array}{l}\text { SS }(+)^{* * * T B} \text { cases in laboratory } \\
\text { register }(n)\end{array}$} \\
\hline Median (min-max) & $43(0-296)$ & $17(0-115)$ & $198(157-239)$ & $35(0-296)$ \\
\hline Cumulative & 2,053 & 929 & 396 & 3,378 \\
\hline \multicolumn{5}{|c|}{ SS $(+)$ TB cases in TB patient register (n) } \\
\hline Median (min-max) & $25(2-126)$ & $9(2-80)$ & $117.5(113-122)$ & $17(0-126)$ \\
\hline Cumulative & 1,011 & 587 & 235 & 1,833 \\
\hline
\end{tabular}

${ }^{*} \mathrm{~TB}=$ tuberculosis; ${ }^{* *} \mathrm{n}=$ number; ${ }^{* *} \mathrm{SS}(+)=$ sputum smear positive.

Table 3: Result of post-stratification analysis.

\begin{tabular}{|c|c|c|c|c|}
\hline & $\begin{array}{l}\text { Public general } \\
\text { hospital }\end{array}$ & $\begin{array}{l}\text { Private } \\
\text { general } \\
\text { hospital }\end{array}$ & $\begin{array}{l}\text { Public } \\
\text { pulmonary } \\
\text { hospital }\end{array}$ & All hospitals \\
\hline Hospitals in the study population $(n)^{*}$ & 72 & 70 & 8 & 150 \\
\hline Hospitals in the sample ( $n$ ) & 31 & 29 & 2 & 62 \\
\hline Post-stratification weight & 2.32 & 2.41 & 4.00 & 2.42 \\
\hline $\begin{array}{l}\text { Weighted cumulative number of } \mathrm{TB}^{* *} \text { cases in } \\
\text { morbidity report }(\mathrm{A})\end{array}$ & 26,066 & 16,518 & 5,696 & 47,153 \\
\hline $\begin{array}{l}\text { Weighted cumulative number of TB cases in TB patient } \\
\text { register (B) }\end{array}$ & 3,972 & 2,752 & 2,792 & 8,521 \\
\hline $\begin{array}{l}\text { Weighted cumulative number of SS }(+)^{* * *} \mathrm{~TB} \text { cases in } \\
\text { laboratory register }(\mathrm{C})\end{array}$ & 4,768 & 2,242 & 1,584 & 8,173 \\
\hline $\begin{array}{l}\text { Weighted cumulative number of SS (+) TB cases in TB } \\
\text { patient register (D) }\end{array}$ & 2,348 & 1,417 & 940 & 4,435 \\
\hline $\begin{array}{l}\text { Adjusted gap of cumulative number TB cases between } \\
\text { TB patient register and morbidity report, applying } \\
\text { referral rate of } 31.5 \% \\
{[(100-(\mathrm{B} / \mathrm{A}))-31.5 \%]}\end{array}$ & $53.3 \%$ & $51.8 \%$ & $19.5 \%$ & $50.4 \%$ \\
\hline $\begin{array}{l}\text { Adjusted gap of cumulative no. SS (+) TB cases } \\
\text { between TB patient register and Lab register, applying } \\
32.6 \% \text { of referral rate } \\
{[(100-(D / C))-32.6 \%]}\end{array}$ & $18.2 \%$ & $4.2 \%$ & $8.1 \%$ & $13.1 \%$ \\
\hline
\end{tabular}


supervision, should also be strengthened to improve practices in the context of PPM-DOTS hospitals.

This study is limited to measure, not explain, the phenomenon of missed opportunities on TB diagnosis and treatment in PPM-DOTS hospitals. The assumed referral rate for sputum smear positive TB cases may be considered too high for Java Island and other areas in Indonesia because the rates were calculated under a closely monitored pilot project. If this is the case, our results in fact underestimate the proportion of cases not administered under DOTS strategy.

\section{Conclusions}

This study found that a substantial proportion of TB patients cared for at PPM-DOTS hospitals are not managed under the DOTS strategy. This represents a missed opportunity for standardized diagnoses and treatment. A combination of strong individual commitment of health professionals, organizational supports, leadership, and relevant policy in hospital and National Tuberculosis Programme may be required to strengthen DOTS implementation in hospitals.

\section{Authors' contributions \\ AP was responsible for developing the research idea, designing the study, exe- cuting the data collection, analysis and interpretation of the results, as well as for the writing of the manuscript. LL and HS contributed to the interpretation of the data, and revision of the manuscript. AU participated in the study design, execution of the data collection, analysis and interpretation of the data as well as in substantially revising the manuscript. AK gave intellectual inputs to the study design, analysis and interpretation of data and performed the crit- ical revision of the manuscript. $A U$ and $A K$ made equal contribution to the study. All authors read and approved the final manuscript.}

\section{Competing interests}

The authors declare that they have no competing interests.

\section{Acknowledgements}

The researchers gratefully acknowledge the assistance of the participating hospitals. We also acknowledge Hari Agus Sanjoto and Mohammad Arifin for their contribution to data collection and data entry. This research was supported by the Sub-Directorate of Tuberculosis, Ministry of Health, Republic of Indonesia and funded by DFID-UK through the World Health Organization (Project: INO TUB 002 XW 06 EC0. P01. A01) and the Centre for Global Health at Umeå University (supported by FAS, the Swedish Council for Working Life and Social Research, grant no 2006-1512).

\section{Author Details}

'Department of Public Health, Faculty of Medicine, Universitas Sebelas Maret, J. Ir. Sutami 36A, Surakarta 57126 Indonesia, ${ }^{2}$ Epidemiology and Global Health, Public Health and Clinical Medicine, Umeå University, Umeå, Sweden, ${ }^{3}$ Department of Public Health, Faculty of Medicine, Universitas Gadjah Mada, Yogyakarta, Indonesia and ${ }^{4}$ Swedish Research School for Global Health, Umeå, Sweden

Received: 27 October 2009 Accepted: 7 May 2010

Published: 7 May 2010

\section{References}

1. Vassal A, Bagdadi S, Bashour H, Zaher H, Maaren PV: Cost-effectiveness of different treatment strategies for tuberculosis in Egypt and Syria. Int J Tuberc Lung Dis 2002, 6:1083-1090.
2. Xu Q, Jin SG, Zhang LX: Cost effectiveness of DOTS and non DOTS strategies for smear-positive pulmonary tuberculosis in Beijing. Biomed Environ Sci 2000, 13:307-313.

3. Baltussen R, Floyd K, Dye C: Cost effectiveness analysis of strategies for tuberculosis control in developing countries. BMJ 10 November 2005.

4. Pursue high-quality DOTS expansion and enhancement: five components of DOTS [http://www.who.int/tb/dots/en/]. accessed on March 9, 2010

5. Uplekar M, Pathania V, Raviglione M: Private practitioners and public health: weak links in tuberculosis control. The Lancet 2001, 358:912-916.

6. Uplekar M: Public-private mix for DOTS: demanding, but delay will only hamper TB control. Int J Tuberc Lung Dis 2003, 7:1113-1114.

7. Uplekar M, Juvekar S, Morankar S, Rangan S, Nunn P: Tuberculosis patients and practitioners in private clinics in India. Int J Tuberc Lung Dis 1998, 2:324-329.

8. Singh AA, Frieden TR, Khatri GR, Garg R: A survey of tuberculosis hospitals in India. Int J Tuberc Lung Dis 2004, 8:1255-1259.

9. Ambe G, Lonnroth K, Dholakia Y, Copreaux J, Zignol M, Borremans N Uplekar M: Every provider counts!: Effect of a comprehensive publicprivate mix approach for TB control in a large metropolitan area in India. Int J Tuberc Lung Dis 2005, 9:562-68.

10. WHO: Engaging All Health Care Providers in TB Control: Guidance on Implementing Public-Private Mix Approaches. Geneva 2006.

11. Ministry of Health Republic of Indonesia: TB Prevalence Survey 2004. Jakarta 2005.

12. Arif K, Ali SA, Amanullah S, Siddiqui I, Khan JA, Nayani P: Physician compliance with national tuberculosis treatment guideline: a university hospital study. Int J Tuberc Lung Dis 1997, 2:225-230.

13. Portero JL, Rubio M: Private practitioners and tuberculosis control in the Philippines: strangers when they meet? Trop Med Int Health 2003, 8:329-335.

14. Lonnroth K, Thuong LM, Lambergts K, Quy HT, Diwan VK: Private tuberculosis care provision associated with poor treatment outcome a comparative cohort analysis of a semi-private chest clinic and the national tuberculosis control programme in Ho Chi Minh City, Vietnam. Int J Tuberc Lung Dis 2003, 7:165-171.

15. Quy HT, Lonnroth K, Lan NTN, Buu TN, Dieu TTN: Treatment result among patients treated by private lung specialists involved in a public-private mix project in Ho Chi Minh City, Vietnam. Int J Tuberc Lung Dis 2003, 7:1139-1146.

16. WHO and the Stop TB Partnership: The Stop TB Strategy: Building on and enhancing DOTS to meet the TB related-Millennium Development Goals. Geneva 2006.

17. Chiang CY, Trebucq A, Billo N, Khortwong P, Elmogazy E, Begum V, Aditama TY, Ansari A, Baral SC, Vianzon RG: A survey of TB services in hospitals in seven large cities in Asia and North Africa. Int J Tuberc Lung Dis 2007, 11:739-746.

18. Loveday M, Thomson L, Chopra M, Ndlela Z: A health system assessment of the Kwazulu-Natal tuberculosis programme in the context of increasing drug resistance. Int J Tuberc Lung Dis 2008, 12:1042-2047.

19. WHO: WHO TB report 2008: Global TB Control Surveillance, Planning and Financing. Geneva 2008.

20. Mantala MJ: Public private mix DOTS in the Philippines. Tuberculosis 2003, 83:173-176.

21. WHO: Public Private Mix for DOTS: Towards Scaling Up. Report of the Third Meeting of the PPM Subgroup for DOTS Expansion. Geneva 2005.

22. Irawati SR, Basri C, Arias MS, Prihatini S, Rintiswati N, Voskens J, Kimerling ME: Hospital DOTS linkage in Indonesia: a model for DOTS expansion into government and private hospitals. Int J Tuberc Lung Dis 2007, 11:33-39.

23. Uplekar M: Stopping tuberculosis: time to turn urgent attention to hospitals. Int J Tuberc Lung Dis 2008, 12:986.

24. Ministry of Health Republic of Indonesia and the Stop TB Partnership: Report of the Joint External TB Monitoring Mission Indonesia 16-27 April 2007. Jakarta 2008.

25. Probandari A, Utarini A, Hurtig A-K: Achieving quality in the Directly Observed Treatment Short-course (DOTS) strategy implementation process: a challenge for hospital Public-Private Mix in Indonesia. Global Health Action 2008.

26. Ministry of Health Republic of Indonesia: Pedoman Nasional Penanggulangan Tuberkulosis. Jakarta 2007 
27. Murthy KJR, Frieden TR, Yazdani A, Hreshikesh P: Public-private partnership in tuberculosis control: experience in Hyderabad, India. Int $J$ Tuberc Lung Dis 2001, 5:354-359.

28. Caminero JA, Billo NE: Involving private practitioners and chest physicians in the control of tuberculosis. Tuberculosis 2003, 83:148-155.

29. Lonnroth K, Tran TU, Thuong LM, Quy HT, Diwan V: Can I afford free treatment?: Perceived consequences of health care provider choices among people with tuberculosis in Ho Chi Minh City, Vietnam. Soc Sci Med 2001, 52:935-948.

30. Nelson EC, Baltaden PB, Huber TB, Mohr JJ, Godfrey MM, Headrick LA, Wasson JH: Micro system in health care: Part 1. Learning from highperforming front-line clinical units. Journal on Quality Improvement 2002, 28:472-493

31. Tuberculosis Coalition for Technical Assistance: International Standards for Tuberculosis Care 2006 [http://www.who.int/entity/tb/publications/2006/ istc report.pdf]. accessed on May 202009

32. Hopewell PC, Pai M, Maher D, Uplekar M, Ravligione MC: International Standards for Tuberculosis Care. Lancet Infectious Diseases 2006, 6:710-725.

33. Miglioni GB, Hopewell PC, Blasi F, Spanevello A, Ravligione MC: Improving the TB case management: The International Standards for TB Care. Eur Respir J 2006, 28:687-690.

34. Lonnroth K, Uplekar M, Blanc L: Hard gains through soft contracts: productive engagement of private providers in tuberculosis control. Bull World Health Organ 2006, 84:876-883.

35. Tuberculosis: Incentives and Enablers [http://www.msh.org/projects/ rpmplus/WhatWeDo/Tuberculosis/Incentives-and-Enablers.cfm] Accessed on May 20, 2009

36. Siddiqi K, Volz A, Armas L, Otero L, Ugaz R, Ochoa E, Gotuzzo E, Torrico F, Newell JN, Walley J, Robinson M, Dieltiens G, Stuyft P Van der: Could clinical audit improve the diagnosis of pulmonary tuberculosis in Cuba, Peru and Bolivia? Trop Med Int Health 2008, 13:566-578.

\section{Pre-publication history}

The pre-publication history for this paper can be accessed here: http://www.biomedcentral.com/1472-6963/10/113/prepub

doi: 10.1186/1472-6963-10-113

Cite this article as: Probandari et al., Missed opportunity for standardized diagnosis and treatment among adult Tuberculosis patients in hospitals involved in Public-Private Mix for Directly Observed Treatment Short-Course strategy in Indonesia: a cross-sectional study BMC Health Services Research 2010, 10:113

\section{Submit your next manuscript to BioMed Central} and take full advantage of:

- Convenient online submission

- Thorough peer review

- No space constraints or color figure charges

- Immediate publication on acceptance

- Inclusion in PubMed, CAS, Scopus and Google Scholar

- Research which is freely available for redistribution

Submit your manuscript at www.biomedcentral.com/submit
Ciomed Central 